\title{
Specialization of agricultural organizations of Chelyabinsk region: analysis and institutional interpretation
}

\author{
Evgenia Zakharova*, Elena Zemtsova, Denis Davydov, Ekaterina Abilova, Tatyana Lushnikova, and Anastasia Tregubova \\ Chelyabinsk State University, Chelyabinsk 454001, Russia
}

\begin{abstract}
The article presents the results of research and analysis of specialization of agricultural organizations of the Chelyabinsk region for the period from 2006 to 2017, which according to the population ecology of organizations has advantages in stable or specific environments. To study the specialization of the organizations of the agro-industrial complex of the Chelyabinsk region, a three-part coefficient of specialization was used, which characterizes the total share of the three values of the studied trait in the total population. Empirical research of agro-industrial complex of Chelyabinsk region allowed performing the analysis of $294 \ldots 194$ organizations for the period 2006...2017. It was found that the arithmetic value of a share of the first three types of products, ordered descending, in the structure of realization of products of agricultural organizations of territories of the region made up $78.09 \ldots 85.08 \%$ and in the structure of sales organizations of the region amounted to $89.71 \ldots 96.86 \%$. It was shown that the analysis of the shares of the first three types of products, ordered in descending order, in the structure of sales of agricultural products can be reduced to the analysis of the shares of the first of the three types of products in this ordered structure. It was found that during the study period, the share of organizations of the agro-industrial complex of the region with the share of proceeds from the sale of grain and leguminous crops in the total revenue of organizations $20 \ldots 80 \%$ amounted to $45.92 \ldots .29 .61 \%$.
\end{abstract}

\section{Introduction}

The modern economic sociology includes two main directions - sociology of markets and sociology of organizations [1-4]. Within these two directions complementary research programs are created and developed, for example, population ecology of organizations [5-7].

Population ecology of organizations transfers many biological laws to a set of organizations. This science studies a set of organizations that have a homogeneous organizational form, and therefore are relatively homogeneous in terms of their vulnerability to environmental changes [8]. Otherwise, the population ecology of organizations equals the set of organizations in biological populations and studies them, as well as changes in organizational forms of populations for the chosen set of observable characteristics which are known to affect the degree of compliance with its surrounding external environment $[9,10]$.

Empirical research in the framework of the population ecology of organizations revealed that the selection mechanism is the leading mechanism of changes in organizations and sectors of the market economy. "Organizational forms are probably failing to evolve - "write M.T. Hannan and J.T. Smith. Freeman in certain environmental conditions because other forms compete successfully with them for basic resources. As long as the resources that sustain organizations are limited and populations have unlimited capacity to expand, competition is inevitable" [11].

M.T. Hannan remarks: "If two populations of organizations supported by identical environmental resources differ in some organizational characteristic, then a population with a characteristic less corresponding to the variables will tend to disappear. Stable equilibrium will then include only one population which can be said to be isomorphic to the environment" [8].

More generally, the upper bound of a variety in a system is determined not only by specific resources but also by additional growth constraints. Thus, the expansion of markets and government regulation mechanisms may, for example, cause a reduction in the number of restrictions for local environments. M.T. Hannan and J. Freeman write: “.. . the process of expanding the economic and political center must, therefore, have a tendency to replace some local restrictions with more unified restrictions more uniform" [8].

Population ecology of organizations postulates that a single population of organizations occupies its market niche in an unstable environment in which the population has a stable competitive advantage. "Faced with unstable environments," - write researchers M.T. Hannan and J. Freedman, - organizations need to develop a generalist structure that is not best adapted to 
any of the configurations of the external environment but is optimal for the entire set of configurations" [8].

Population ecology of organizations states that specialization will always have advantages in stable or defined environments and generalism is not always optimal in uncertain environments.

"If the environment varies between the states in unpredictable manner imposing very different requirements to the organization, and the duration of the state of the external environment is negligible relative to the lifespan of the organization... populations of organizations that have chosen the specialization will be in a better position than those who chose generalism" $[8,12,13]$.

The study of specialization of organizations reveals the result of competition for resources between organizations of different populations.

The purpose of the study is to analyze the specialization of the organizations of the agro-industrial complex of the Chelyabinsk region which is characterized by the industrial type of the structure of the gross regional product.

In accordance with the purpose of the study the following tasks are set:

- to carry out a comparative analysis of the normalized values of the arithmetic means of shares of the first three types of products, ordered descending, in the structure of realization of products of agricultural organizations of Chelyabinsk region for the period from 2006 to 2017 ;

- to carry out a comparative analysis of the distribution of agricultural organizations by the share of proceeds from the sale of grain and leguminous crops in the total revenue of agricultural organizations of the Chelyabinsk region for the period from 2006 to 2017 .

\section{Materials and methods}

When solving the tasks set in this study, two approaches to the empirical study of the specialization of organizations of the agro-industrial complex of the Chelyabinsk region were formulated, to the analysis of its results.

In the first approach, the specialization coefficient is calculated for the three, four, six or eight largest units of the set of values of the studied trait. For example, $C R_{3}$ is a three-part index of specialization that characterizes the total share of the three values of the studied trait in the total population:

$$
C R_{3}=\sum_{i=1}^{3} p_{i}
$$

where $p_{i}-$ is a proportion of $i$-value of the studied trait.

The second approach calculates inequality indicators which properties are determined by the axioms of inequality measurement, namely: redistribution, scale independence, duplication of observations, anonymity and additivity [14]. Only one class of indicators namely generalized entropy indicators satisfies all the above requirements $(G E)$ :

$$
G E(\alpha)=\frac{1}{\alpha^{2}-\alpha}\left[\frac{1}{n} \sum_{i=1}^{n}\left(\frac{x_{i}}{\bar{x}}\right)^{\alpha}-1\right],
$$

where $\alpha-$ is a parameter that takes any value from $-\infty$ to $+\infty$

$n$ - is a population size;

$x_{i}-$ is a $i$-value of the studied trait.;

$\bar{x}-$ is the arithmetic mean of the studied trait.

If the parameter $\alpha$ is 0 , the index of the logarithmic mean deviation, which gives greater weight to the differences of the studied trait at the bottom of the distribution, has the form:

$$
G E(0)=-\frac{1}{n} \sum_{i=1}^{n} \log \left(\frac{x_{i}}{\bar{x}}\right)=\frac{1}{n} \sum_{i=1}^{n} \log \left(\frac{\bar{x}}{x_{i}}\right) .
$$

If the parameter $\alpha$ is equal to 1 , then Theil index [15], which gives equal weights to the observations over the entire distribution scale, has the form:

$$
G E(1)=\frac{1}{n} \sum_{i=1}^{n}\left(\frac{x_{i}}{\bar{x}}\right) \log \left(\frac{x_{i}}{\bar{x}}\right) .
$$

If the parameter $\alpha$ is 2 , the total entropy index, which gives greater weight to the differences in the studied trait at the top of the distribution, has the form:

$$
\begin{aligned}
& G E(2)=\frac{1}{2}\left[\frac{1}{n} \sum_{i=1}^{n}\left(\frac{x_{i}}{\bar{x}}\right)^{2}-1\right]= \\
& =\frac{1}{2 \bar{x}^{-2}}\left[\frac{1}{n} \sum_{i=1}^{n}\left(x_{i}-\bar{x}\right)^{2}\right]=\frac{1}{2} V^{2},
\end{aligned}
$$

where $V-$ is a coefficient of variation.

The Atkinson index [16, p. 244-263] has the form:

$$
A_{\varepsilon}=1-\left[\frac{1}{n} \sum_{i=1}^{n}\left(\frac{x_{i}}{\bar{x}}\right)^{1-\varepsilon}\right]^{1 /(1-\varepsilon)},
$$

where $\varepsilon-$ is a parameter of inequality deviation.

If $\alpha=1-\varepsilon$, the generalized entropy indices become conditionally equivalent to the Atkinson index for the values $\alpha<1$ [17]. The Atkinson index satisfies the requirement of additivity, that is, it decomposes without remainder in the sum of inequality within groups and intergroup inequality [18].

Popular in the theory of industrial markets Gini index does not meet the requirement of the axiom of additivity, if the subvectors of the studied trait intersect [18]. However, despite some limitations, it contains useful information about the form of distribution of the studied trait [19], and has the form:

$$
G=\frac{1}{2 n^{2} \bar{x}} \sum_{i=1}^{n} \sum_{j=1}^{n}\left|x_{i}-x_{j}\right| .
$$

Besides, methods of decomposition of this indicator have been proposed [20-22], but it is possible to decompose it without a residue only if the subvectors of the studied trait do not intersect [23].

For an empirical study of the specialization of the organizations of the agro-industrial complex of the Chelyabinsk region for the period from 2006 to 2017, a 
three-part index of specialization $\left(C R_{3}\right)$ was used, methods of regression analysis and nonparametric statistics were used.

The information base of the research is represented by scientific economic literature, statistical data and analytical information of the Ministry of agriculture of the Chelyabinsk region, in particular, the data of forms 9 and 13 of the annual financial statements of organizations of the agro-industrial complex of the Chelyabinsk region for the period from 2006 to 2017.

\section{Results}

The empirical study of agro-industrial complex of the Chelyabinsk region made it possible to perform analysis $294 \ldots 194$ for the period from $2006 . .2017$, and also to assess the areas of specialization of the region according to the share of the first three types of products, ordered descending, in the structure of realization of products of agro-industrial districts of the Chelyabinsk region. As a result, it was found that the average arithmetic values of the shares of the first three types of products, ordered in descending order, in the structure of sales of products of agricultural organizations of the region amounted to $78.09 \ldots 85.08 \%$ (standard deviation is 7.53 ...12).

The empirical study of specialization of the organizations of agro-industrial complex of the region has allowed establishing that the arithmetic value of shares of the first three types of products, ordered descending, in the structure of sales organizations of the region amounted to $89.71 . .96 .86 \%$ (standard deviation is 2.35...4.15) (Appendix A and Figure 1).

A comparative analysis of the normalized values of the arithmetic means of shares of the first three types of products, ordered descending, in the structure of realization of products of agricultural organizations of the Chelyabinsk region (Figure 1) has allowed using the nonparametric Mann-Whitney U-test to identify three periods, the average of the ranks which amounted to 69.42 and 136.35 and also 173.74 respectively (Table 1).

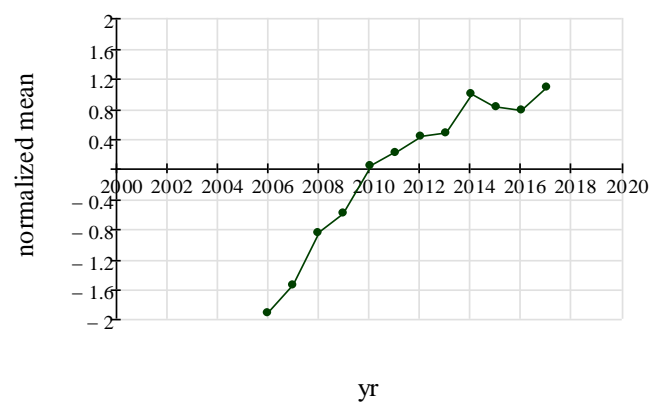

Fig. 1. Normalized values of the arithmetic means of shares of the first three types of products, ordered descending, in the structure of realization of products of agricultural organizations of the Chelyabinsk region (from 2006 to 2017).

The first period is from 2006 to 2009 . The arithmetic mean of the shares of the first three types of products, ordered in descending order, in the structure of sales of products of agricultural organizations of the Chelyabinsk region was $91.31 \%$. The minimum value of this indicator in this period is $89.71 \%$, and the maximum value is $92.78 \%$ (Table 1 ).

The second period is from 2010 to 2013. The arithmetic mean of the shares of the first three types of products, ordered in descending order, in the structure of sales of products of agricultural organizations of the Chelyabinsk region was $94.84 \%$. The minimum value of this indicator in this period is $94.25 \%$, and the maximum value is $95.28 \%$ (Table 1 ).

The third period is from 2014 to 2017 . The arithmetic mean of the shares of the first three types of products, ordered in descending order, in the structure of sales of products of agricultural organizations of the Chelyabinsk region was $96.37 \%$. The minimum value of this indicator in this period is $96.01 \%$, and the maximum value is $96.86 \%$ (Table 1).

Table 1. Comparative analysis of the normalized values of the arithmetic means of shares of the first three types of products, ordered descending, in the structure of realization of products of agricultural organizations of the Chelyabinsk region (nonparametric Mann-Whitney U-test).

\begin{tabular}{|c|c|c|c|}
\hline Period & $\mathbf{2 0 0 6 . . 2 0 0 9}$ & $\mathbf{2 0 1 0 . . 2 0 1 3}$ & $\mathbf{2 0 1 4 . . . 2 0 1 7}$ \\
\hline $\mathbf{2 0 0 6 \ldots . . 2 0 0 9}$ & - & & \\
\hline $\mathbf{2 0 1 0 . . . 2 0 1 3}$ & $\mathrm{H}_{1}(\alpha=0.000)$ & - & \\
\hline $\mathbf{2 0 1 4 \ldots . 2 0 1 7}$ & $\mathrm{H}_{1}(\alpha=0.000)$ & $\mathrm{H}_{1}(\alpha=0.000)$ & - \\
\hline$\overline{\boldsymbol{X}}$ & $\mathbf{6 9 . 4 2}$ & $\mathbf{1 3 6 . 3 5}$ & $\mathbf{1 7 3 . 7 4}$ \\
\hline
\end{tabular}

Notes:

$H_{0} \quad$ - the hypothesis of equality of the mean values of two independent samples is confirmed;

$H_{1} \quad$ - the hypothesis of equality of the mean values of two independent samples has not been confirmed.

Sources:

Ministry of agriculture of the Chelyabinsk region

Using regression analysis, we get the equation of classical pair linear regression, where: $y$ is the normalized value of the arithmetic means of shares of the first three types of products, ordered descending, in the structure of realization of products of agricultural organizations of the Chelyabinsk region; $x$ is the normalized values of arithmetic means of shares of the first three types of products, ordered descending, in the structure of realization of products of agricultural organizations of the Chelyabinsk region (Figure 2).

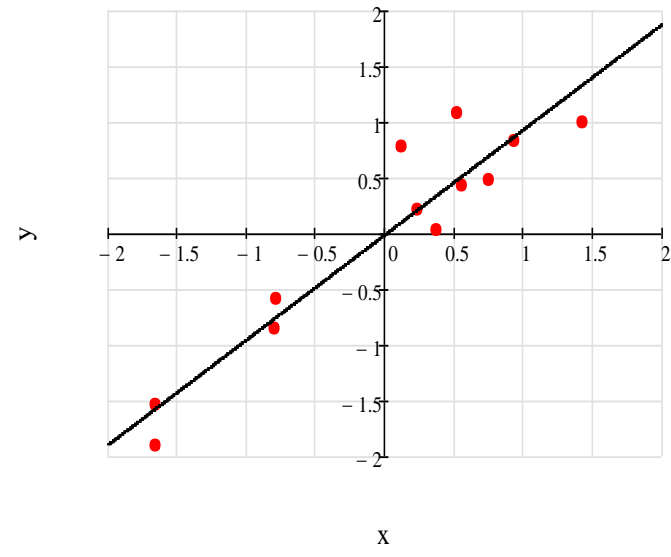

Fig. 2. Equation of classical pair linear regression. 
The equation of the classical pair linear regression has the form:

$$
y=0.943 x \text {. }
$$

The coefficient $b$ of the linear regression equation is statistically significant, as indicated by the values of the $t$-statistics (Table 2).

Table 2. Variables of empirical research model

\begin{tabular}{|c|c|c|c|c|c|c|}
\hline \multirow{2}{*}{$\begin{array}{c}\text { Model } \\
y\end{array}$} & \multicolumn{2}{|c|}{ Coefficients } & \multirow{2}{*}{$\boldsymbol{*}$} & \multirow{\alpha}{*}{$\boldsymbol{c}$} & \multicolumn{2}{|c|}{$C I$} \\
\cline { 2 - 5 } \cline { 6 - 7 } & $\boldsymbol{b}$ & $\boldsymbol{s}_{\boldsymbol{b}}$ & & & $A$ & $B$ \\
\hline$a$ & 0.000 & 0.101 & 0.000 & 0.999 & -0.22 & 0.225 \\
\hline$b$ & 0.943 & 0.105 & 8.945 & 0.000 & 0.708 & 1.178 \\
\hline
\end{tabular}

Notes:

$s_{b}-$ standard error of parameters of pair linear regression;

$t$ - Student's criterion;

$\alpha \quad$ significance level $(\alpha=0.05)$.

The conclusion is valid in respect of the equation in general, this is indicated by the value of Fisher-Snedecor criterion (Table 3 ).

Table 3. Summary for the pair linear regression model

\begin{tabular}{|c|c|c|c|c|c|}
\hline Model & $R$ & $R^{2}$ & $S^{2}$ & $F$ & $\alpha$ \\
\hline$y$ & 0.943 & 0.889 & 0.350 & 80.012 & 0.000 \\
\hline
\end{tabular}

Notes:

$R-$ correlation coefficient;

$R^{2}$ - determination coefficient;

$S^{2}$ - the standard error of estimation;

$F$ - Fisher-Snedecor criterion;

$\alpha \quad-$ significance level $(\alpha=0.05)$.

Thus, the characteristics of the model of the empirical study allow concluding that the increase in normalized values to the average value shares of the first of the three types of products, ordered descending, in the structure of realization of products of agricultural organizations of the Chelyabinsk region on $1.00 \%$ of their average values leads to increased normalized values of the average proportion of the first three types of products, ordered descending, in the structure of realization of products of agricultural organizations of the Chelyabinsk region on average $0.943 \%$.

Consequently, the analysis of the share of the first three types of products, ordered descending, in the structure of realization of products of agricultural organizations of the Chelyabinsk region can be reduced to the analysis of the shares of the first three types of products, ordered descending, in the structure of realization of products of agricultural organizations of the Chelyabinsk region.

The empirical study of agro-industrial complex of the Chelyabinsk region with the mountain forest, the Northern forest-steppe, the Southern forest-steppe and the wall of climatic zones made it possible to perform distribution of organizations by share of revenue from sales of grain and leguminous crops in the total revenue of the organizations (Appendix B).

For example, the first group includes organizations of the agro-industrial complex of the region with a share of proceeds from the sale of grain and leguminous crops 0 $\%$. During the researched period 2006-2017, the average share of organizations in this group was $16.45 \%$. The minimum value of this indicator in this period is $6.46 \%$, and the maximum value is $22.85 \%$ (Figure 3 ).

To the eleventh group we refer the organizations of agro-industrial complex of area with a share of proceeds from realization of grain and leguminous cultures of $90 \ldots 100 \%$. During the researched period 2006-2017, the average share of the Chelyabinsk region organizations in this group was $24.57 \%$. The minimum value of this indicator in this period is $16.85 \%$, and the maximum value is $34.08 \%$ (Figure 3 ).

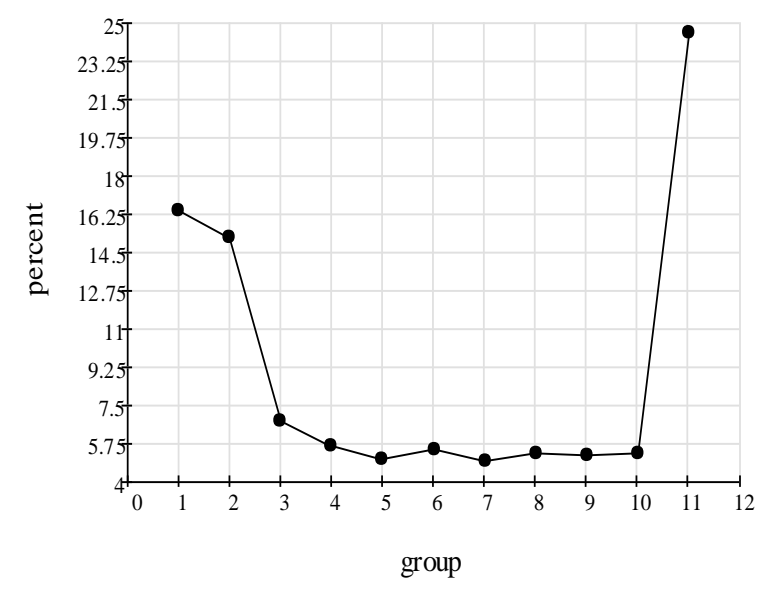

Fig. 3. Distribution of agricultural organizations of the Chelyabinsk region by the share of proceeds from the sale of grain and leguminous crops in the total revenue of agricultural organizations (from 2006 to 2017).

Aggregation of distribution groups of agricultural organizations of the Chelyabinsk region by the share of proceeds from the sale of grain and leguminous crops in the total revenue of organizations allows distinguishing four groups (Table 4).

Table 4. Distribution of agricultural organizations of the Chelyabinsk region by the share of proceeds from the sale of grain and leguminous crops in the total revenue of agricultural organizations (aggregated variant)

\begin{tabular}{|c|c|c|c|c|}
\hline Year & $0 \ldots 20$ & $20 \ldots 80$ & $80 \ldots 100$ & 0 \\
\hline 2006 & 22.79 & 45.92 & 24.83 & 6.46 \\
\hline 2007 & 23.96 & 40.63 & 26.04 & 9.38 \\
\hline 2008 & 24.01 & 35.48 & 30.47 & 10.04 \\
\hline 2009 & 23.13 & 34.52 & 25.27 & 17.08 \\
\hline 2010 & 32.21 & 23.97 & 20.97 & 22.85 \\
\hline 2011 & 15.35 & 35.83 & 30.31 & 18.50 \\
\hline 2012 & 24.27 & 28.87 & 28.45 & 18.41 \\
\hline 2013 & 25.54 & 27.27 & 26.41 & 20.78 \\
\hline 2014 & 19.82 & 22.03 & 36.56 & 21.59 \\
\hline 2015 & 18.48 & 25.59 & 34.60 & 21.33 \\
\hline 2016 & 17.53 & 30.41 & 35.05 & 17.01 \\
\hline 2017 & 17.32 & 29.61 & 39.11 & 13.97 \\
\hline $\bar{X}$ & 22.03 & 31.68 & 29.84 & 16.45 \\
\hline
\end{tabular}

Sources:

Ministry of agriculture of the Chelyabinsk region.

To the second aggregated group we refer the organizations of agro-industrial complex of the region with the share of proceeds from the sale of grain and leguminous crops in the total revenue of organizations 
Table 6. Arithmetic means of shares of the first three types of products, ordered in descending order, in the structure of product sales agricultural organizations of the Chelyabinsk region.

\begin{tabular}{|c|c|c|c|c|c|c|c|c|c|c|c|c|c|}
\hline Territory & 2006 & 2007 & 2008 & 2009 & 2010 & 2011 & 2012 & 2013 & 2014 & 2015 & 2016 & 2017 & $\bar{X}$ \\
\hline Agapovsky & 90.53 & 89.32 & 89.79 & 92.19 & 94.25 & 94.27 & 92.74 & 96.90 & 96.95 & 96.92 & 97.60 & 98.09 & 94.26 \\
\hline Argayashskaya & 84.84 & 85.30 & 7.63 & 37.97 & 90.24 & 90.66 & 95.78 & 93.55 & 95.78 & 96.90 & 92.99 & 3.01 & 91.82 \\
\hline Bredy & 90.85 & 95.49 & 95.43 & 93.00 & 94.77 & 94.36 & 91.80 & 91.69 & 93.93 & 96.27 & 98.64 & 98.16 & 94.56 \\
\hline Varna & 87.58 & 92.26 & 95.45 & 91.39 & 94.53 & 91.63 & 93.16 & 93.72 & 95.62 & 94.83 & 96.92 & 96.12 & 94.12 \\
\hline Verkhneura & 93.14 & 90.89 & 96.57 & 96.34 & 98.14 & 95.15 & 96.66 & 98.15 & 98.19 & 93.53 & 94.73 & 96.24 & 96.29 \\
\hline Masculatory & 81.99 & 88.73 & 86.19 & 96.07 & 95.89 & 96.91 & 97.27 & 98.81 & 96.14 & 94.07 & 95.43 & 93.53 & 95.66 \\
\hline Kach: & 91.33 & 94.43 & 95.16 & 91.97 & 87.52 & 92.40 & 93.58 & 94.17 & 98.39 & 99.09 & 97.22 & 98.81 & 94.30 \\
\hline Kasli & 83.46 & 88.24 & 90.75 & 93.57 & 95.24 & 93.85 & 96.52 & 96.99 & 96.17 & 90.89 & 81.08 & 90.86 & 92.23 \\
\hline Kizil & 91.67 & 93.62 & 93.08 & 91.36 & 95.01 & 97.28 & 96.35 & 96.72 & 97.98 & 99.58 & 99.35 & 99.61 & 96.53 \\
\hline Krasnoarme & 91.36 & 90.82 & 91.03 & 94.42 & 97.07 & 93.28 & 95.43 & 94.28 & 97.49 & 96.50 & 95.93 & 96.62 & 94.92 \\
\hline Kuna: & .57 & 94.63 & 95.55 & 97.11 & 97.82 & 96.34 & 99.38 & 99.20 & 99.96 & 99.95 & 99.82 & 99.45 & 98.51 \\
\hline Naga & 89.15 & 83.13 & 89.95 & 89.72 & 87.46 & 90.91 & 90.20 & 89.73 & 92.77 & 95.56 & 100.00 & 98.86 & 90.07 \\
\hline Nyazepet & 93.18 & 90.32 & 91.52 & 88.14 & 96.61 & 97.79 & 98.33 & 94.86 & 96.90 & 98.49 & 98.04 & 100.00 & 96.76 \\
\hline Oktyab & 89.50 & 90.70 & 93.41 & 90.97 & 94.08 & 95.04 & 93.42 & 94.04 & 96.77 & 96.83 & 96.08 & 96.83 & 94.06 \\
\hline Sosno & 88.75 & 88.18 & 90.04 & 95.28 & 96.65 & 96.23 & 97.48 & 96.28 & 96.00 & 96.70 & 97.46 & 98.91 & 96.25 \\
\hline Troit & 99 & 93.30 & 95.06 & 95.80 & 94.84 & 94.67 & 94.07 & 96.42 & 96.75 & 94.48 & 96.83 & 97.74 & 94.95 \\
\hline SP & 89.12 & 92.32 & 93.20 & 90.75 & 97.66 & 98.41 & 96.26 & 96.51 & 99.96 & 98.92 & 98.85 & 94.83 & 96.39 \\
\hline Uyskiy & 87.82 & 91.17 & 91.88 & 93.69 & 97.91 & 97.94 & 97.76 & 97.96 & 97.21 & 97.79 & 96.37 & 99.37 & 97.48 \\
\hline Chebarkul & 87.43 & 87.19 & 88.19 & 94.72 & 93.29 & 92.61 & 96.08 & 95.33 & 98.07 & 96.28 & 96.80 & 98.07 & 95.03 \\
\hline Chesn & 86.10 & 88.03 & 89.19 & 88.06 & 84.29 & 90.51 & 89.24 & 89.36 & 89.37 & 87.74 & 89.64 & 90.60 & 89.21 \\
\hline nelyabinsk & 90.49 & 91.21 & 92.92 & 93.20 & 94.58 & 94.61 & 94.91 & 95.27 & 96.52 & 96.11 & 96.84 & 97.44 & 94.76 \\
\hline $\bar{X}$ & 89.71 & 90.57 & 92.17 & 92.78 & 94.25 & 94.68 & 95.18 & 95.28 & 96.52 & 96.11 & 96.01 & 96.86 & 94.93 \\
\hline$M_{e}$ & 89.50 & 90.82 & 91.88 & 93.00 & 95.01 & 94.67 & 96.08 & 96.11 & 96.77 & 96.70 & 96.83 & 98.07 & 95.55 \\
\hline$\widetilde{X}$ & -1.90 & -1.53 & -0.85 & -0.59 & 0.04 & 0.22 & 0.43 & 0.48 & 1.01 & 0.83 & 0.79 & 1.08 & 0.33 \\
\hline$\widetilde{M}_{e}$ & -1.66 & -1.52 & -1.10 & -0.66 & 0.12 & -0.01 & 0.54 & 0.55 & 0.81 & 0.78 & 0.83 & 1.30 & 0.33 \\
\hline
\end{tabular}

\section{Notes:}

$\bar{X}$ and $\widetilde{X} \quad-$ arithmetic mean and the normalized value of the arithmetic mean;

$M_{e}$ and $\widetilde{M}_{e} \quad-$ median and normalized mean of median.

Table 7. The distribution of agricultural organizations of the Chelyabinsk region

by the share of proceeds from the sale of grain and leguminous crops in the total revenue of agricultural organizations.

\begin{tabular}{|c|c|c|c|c|c|c|c|c|c|c|c|c|c|c|}
\hline Group & Interval & 2006 & 2007 & 2008 & 2009 & 2010 & 2011 & 2012 & 2013 & 2014 & 2015 & 2016 & 2017 & $\overline{\bar{X}}$ \\
\hline \multicolumn{15}{|c|}{ amount } \\
\hline 1 & 0 & 19 & 27 & 28 & 48 & 61 & 47 & 44 & 48 & 49 & 45 & 33 & 25 & 40 \\
\hline 2 & $0 \ldots 10$ & 37 & 41 & 44 & 43 & 58 & 28 & 35 & 50 & 36 & 26 & 26 & 25 & 37 \\
\hline 3 & $10 \ldots 20$ & 30 & 28 & 23 & 22 & 28 & 11 & 23 & 9 & 9 & 13 & 8 & 6 & 18 \\
\hline 4 & $20 \ldots 30$ & 31 & 20 & 23 & 13 & 11 & 9 & 17 & 11 & 7 & 13 & 8 & 8 & 14 \\
\hline 5 & $30 \ldots 40$ & 13 & 16 & 10 & 25 & 13 & 16 & 9 & 13 & 10 & 7 & 11 & 8 & 13 \\
\hline 6 & $40 \ldots 50$ & 26 & 21 & 20 & 23 & 11 & 17 & 10 & 9 & 8 & 9 & 4 & 11 & 14 \\
\hline 7 & $50 \ldots 60$ & 18 & 12 & 13 & 7 & 14 & 20 & 12 & 13 & 8 & 7 & 11 & 10 & 12 \\
\hline 8 & $60 \ldots 70$ & 23 & 26 & 15 & 17 & 8 & 14 & 16 & 5 & 10 & 7 & 11 & 8 & 13 \\
\hline 9 & $70 \ldots 80$ & 24 & 22 & 18 & 12 & 7 & 15 & 5 & 12 & 7 & 11 & 14 & 8 & 13 \\
\hline 10 & $80 \ldots 90$ & 12 & 16 & 19 & 13 & 11 & 22 & 12 & 5 & 11 & 13 & 12 & 9 & 13 \\
\hline 11 & $90 \ldots 100$ & 61 & 59 & 66 & 58 & 45 & 55 & 56 & 56 & 72 & 60 & 56 & 61 & 59 \\
\hline \multicolumn{2}{|c|}{ Total } & 294 & 288 & 279 & 281 & 267 & 254 & 239 & 231 & 227 & 211 & 194 & 179 & 245 \\
\hline \multicolumn{15}{|c|}{ percent } \\
\hline 1 & 0 & 6.46 & 9.38 & 10.04 & 17.08 & 22.85 & 18.50 & 18.41 & 20.78 & 21.59 & 21.33 & 17.01 & 13.97 & 16.45 \\
\hline 2 & $0 \ldots 10$ & 12.59 & 14.24 & 15.77 & 15.30 & 21.72 & 11.02 & 14.64 & 21.65 & 15.86 & 12.32 & 13.40 & 13.97 & 15.21 \\
\hline 3 & $10 \ldots 20$ & 10.20 & 9.72 & 8.24 & 7.83 & 10.49 & 4.33 & 9.62 & 3.90 & 3.96 & 6.16 & 4.12 & 3.35 & 6.83 \\
\hline 4 & $20 \ldots 30$ & 10.54 & 6.94 & 8.24 & 4.63 & 4.12 & 3.54 & 7.11 & 4.76 & 3.08 & 6.16 & 4.12 & 4.47 & 5.64 \\
\hline 5 & $30 \ldots 40$ & 4.42 & 5.56 & 3.58 & 8.90 & 4.87 & 6.30 & 3.77 & 5.63 & 4.41 & 3.32 & 5.67 & 4.47 & 5.07 \\
\hline 6 & $40 \ldots 50$ & 8.84 & 7.29 & 7.17 & 8.19 & 4.12 & 6.69 & 4.18 & 3.90 & 3.52 & 4.27 & 2.06 & 6.15 & 5.53 \\
\hline 7 & $50 \ldots 60$ & 6.12 & 4.17 & 4.66 & 2.49 & 5.24 & 7.87 & 5.02 & 5.63 & 3.52 & 3.32 & 5.67 & 5.59 & 4.94 \\
\hline 8 & $60 \ldots 70$ & 7.82 & 9.03 & 5.38 & 6.05 & 3.00 & 5.51 & 6.69 & 2.16 & 4.41 & 3.32 & 5.67 & 4.47 & 5.29 \\
\hline 9 & $70 \ldots 80$ & 8.16 & 7.64 & 6.45 & 4.27 & 2.62 & 5.91 & 2.09 & 5.19 & 3.08 & 5.21 & 7.22 & 4.47 & 5.19 \\
\hline 10 & $80 \ldots 90$ & 4.08 & 5.56 & 6.81 & 4.63 & 4.12 & 8.66 & 5.02 & 2.16 & 4.85 & 6.16 & 6.19 & 5.03 & 5.27 \\
\hline 11 & $90 \ldots 100$ & 20.75 & 20.49 & 23.66 & 20.64 & 16.85 & 21.65 & 23.43 & 24.24 & 31.72 & 28.44 & 28.87 & 34.08 & 24.57 \\
\hline \multicolumn{2}{|c|}{ Total } & 100.00 & 100.00 & 100.00 & 100.00 & 100.00 & 100.00 & 100.00 & 100.00 & 100.00 & 100.00 & 100.00 & 100.00 & 100.00 \\
\hline
\end{tabular}




\section{References}

1. V.V. Radaev, ed., Market Analysis in Contemporary Economic Sociology: A Collection of Articles (Moscow, 2008)

2. V.V. Radaev, ed., The West Economic Sociology: Chrestomathy of Contemporary Classics (Moscow, 2004)

3. T.N. Klemina, ed., Organization Theory: Chrestomathy (St Petersburg, 2010)

4. V.V. Radaev, ed., Economic Sociology: New Approaches to Institutional and Network Analysis (Moscow, 2002)

5. L.A. Valitova, V.L. Tambovcev, RZhM, 2, 109-118 (2005)

6. V.V. Radaev, RZhM, 2, 99-108 (2005)

7. V.V. Radaev, Economic Sociology (Moscow, 2008)

8. M. Hannan, J. Freeman, Organization Theory: Chrestomathy, 417-459 (2010)

9. H. Aldrich, The West Economic Sociology: Chrestomathy of Contemporary Classics, 211-225 (2004)
10. W. Barnett, ARS, 1, 217-236 (1995)

11. M. Hannan, J. Freeman, AJS, 5, 929-964 (1977)

12. G.R. Carroll, Organization Theory: Chrestomathy, 460-486 (2010)

13. G.R. Carroll, M. Hannan, Organization Theory: Chrestomathy, 487-516 (2010)

14. F.A. Cowell, DARP, 36 (1998)

15. H. Theil, Economics and Information Theory (Amsterdam, 1967)

16. A.B. Atkinson, JET, 2, 244-263 (1970)

17. F.A. Cowell, RES, 52, 135-151 (1985)

18. A.F. Shorrocks, Econometrica, 3, 613-625 (1980)

19. A.L. Luk'yanova, WP3, 6 (2007)

20. G. Pyatt, EJ, 86, 243-255 (1976)

21. R. Lerman, S. Yitzhaki, RIW, 37, 313-329 (1991)

22. G.S. Fields, WW-BPP, 1, 1-38 (2003)

23. M.N. Tolmachev, Statistical Study of Interregional Inequality in Agricultural Production (Saratov, 2012)

\footnotetext{
Corresponding author: jaz@bk.ru
} 